\title{
The Prevalence of Helicobacter pylori Infection in a Quaternary Hospital in Canada
}

\author{
Philippe Willems ${ }^{\mathrm{a}, \mathrm{c}}$, Janie de Repentigny ${ }^{\mathrm{a}}$, Galab M. Hassan ${ }^{\mathrm{a}}$, Sacha Sidani ${ }^{\mathrm{a}}$, \\ Genevieve Soucy ${ }^{\mathrm{b}}$, Mickael Bouin ${ }^{\mathrm{a}}$
}

\begin{abstract}
Background: Helicobacter pylori (H. pylori) prevalence in Canada has been estimated to be around $20 \%$ to $30 \%$. However, H. pylori prevalence is declining in industrialized countries. We conducted a retrospective study on a population of patients referred for esophagogastroduodenoscopy (EGD) in a Canadian quaternary hospital to see the current prevalence of $H$. pylori infection and identify its main risk factors.
\end{abstract}

Methods: We performed a retrospective cross-sectional study from the Electronic Medical Records of 500 patients who visited our endoscopy clinic and who had biopsies to search for $H$. pylori infection. In addition to the outcome of the biopsies, we collected demographic characteristics of patients, EGD indication and endoscopic findings.

Results: The overall prevalence of $H$. pylori was $13.0 \%(65 / 500)$ among our population. We found no association with age, sex, tobacco or alcohol consumption. However, we noticed a significantly higher prevalence of $H$. pylori among African $(25.0 \% ; 8 / 32)$, Asian $(30.8 \% ; 4 / 13)$ and South American $(34.9 \% ; 15 / 43)$ born subjects when compared to the Caucasian group $(8.0 \%$; 28/350) $($ all $\mathrm{P}<0.05)$.

Conclusions: The prevalence of $H$. pylori in Canada is declining, particularly among its Caucasian population. The race seems to be the strongest risk factor associated with this infection.

Keywords: H. pylori; H. pylori prevalence; Endoscopy

\section{Introduction}

Helicobacter pylori (H. pylori) infection is the most common

Manuscript submitted September 12, 2020, accepted September 29, 2020

Published online November 3, 2020

${ }^{a}$ Gastroenterology Division, Centre Hospitalier de l'Universite de Montreal (CHUM), Montreal, QC, Canada

'Pathology Division, Centre Hospitalier de l'Universite de Montreal (CHUM), Montreal, QC, Canada

${ }^{\mathrm{c} C o r r e s p o n d i n g ~ A u t h o r: ~ P h i l i p p e ~ W i l l e m s, ~ G a s t r o e n t e r o l o g y ~ D i v i s i o n, ~ C e n t r e ~}$ Hospitalier de l'Universite de Montreal (CHUM), 900, rue Saint-Denis, pavillon R, Montreal, QC H2X 0A9, Canada. Email: philippe.willems@umontreal.ca

doi: https://doi.org/10.14740/jocmr4348 bacterial infection in humans and affects $50 \%$ to $80 \%$ of the world's population $[1,2]$. H. pylori is considered a class I carcinogen by the World Health Organization (WHO) and leads to gastric cancer, peptic ulcer and gastritis [3-6]. In Western countries, its prevalence is estimated to be around $30 \%$ with considerable variation in the reported $H$. pylori infection prevalence from one study to another [6-9]. Several tests are available to detect $H$. pylori in symptomatic or non-symptomatic patients. The variability between these tests could explain the differences in the reported prevalence from one study to another $[7,10]$. It has also been shown that the prevalence of $H$. pylori is on the decline in Western countries in recent years due to the effective management of the infection by both curative and preventive approaches, mainly the effectiveness of antibiotics and improvement of hygiene conditions $[5,11,12]$.

In Canada, the prevalence of $\mathrm{H}$. pylori is estimated to be between $20 \%$ and $30 \%$, with one study showing a seroprevalence of $23 \%$ in Ontario $[13,14]$. Canadian populations with the highest prevalence of $H$. pylori are immigrants, seniors (> 65 years of age), and Canadian First Nations with a prevalence of $37.9 \%$ in a recent study $[15,16]$. However, there is very little data on H. pylori prevalence in the province of Quebec and there have been no recent studies.

Endoscopic biopsies with histopathological research of H. pylori infection are often considered the gold standard for diagnosis because of their excellent sensitivity and specificity $[4,17,18]$. It has also been demonstrated that the sensitivity of the histopathological diagnosis depends on the number and location of the biopsies in the stomach and on the use of proton pump inhibitors (PPIs) or antibiotics within for weeks of the esophagogastroduodenoscopy (EGD) [19-21]. The recommendations from Canadian and most other major medical societies are to perform three antral biopsies (antrum and small curvature) and two biopsies in the fundus at the large curvature, because the microorganism may migrate to more proximal niches with the development of gastric mucosal atrophy and the use of PPI $[5,6,17]$. Despite these recommendations, a recent Canadian study found that $60 \%$ of the patients had biopsies at only one site (antrum or corpus) and $47 \%$ were on PPIs at the time of the EGD [22].

The main objective of our study was to evaluate the histopathological prevalence of $H$. pylori in symptomatic patients referred for EGD. The secondary objectives were to study the demographic characteristics associated with the infection and to study the quality of the samples taken during endoscopy for the purpose of $H$. pylori detection. 


\section{Materials and Methods}

This is a cross-sectional, retrospective study. This study was conducted in compliance with the ethical standards of the responsible institution on human subjects as well as with the Helsinki Declaration and was approved by our local Institution Review Board prior to initiation. We used records of patients who had biopsies made during EGD procedure at the SaintLuc Hospital of Centre Hospitalier de l'Universite de Montreal (CHUM) with a specific request for detection of $H$. pylori infection.

\section{Population}

Between December 1 and July 31, 2011 in our institution, 1,351 EGD exams had gastric biopsies with a request for $H$. pylori detection. The files of those exams were studied from our pathology database in a chronological order until the inclusion of the first 500 files. All files with a specific request for $H$. pylori occurrence on gastric biopsies taken during EGD were eligible for the study. We excluded patients with incomplete endoscopy report information. There were no other exclusion criteria.

\section{Studied criteria}

The variables collected were the sex, age, race, smoking status, alcohol consumption (more than 10 drinks per week), indication of the EGD, endoscopic findings, number and location of biopsies, presence or absence of $H$. pylori in the pathology report, the use of antisecretory agents (PPIs or $\mathrm{H} 2$ blockers) and/ or antibiotics for any reason at the time of the EGD. Depending on the race of the patient, our population was divided into four groups: Caucasian, Asian (for Asia and the Middle East), African and South American (for South America, Central America and the Caribbean) groups, depending on their origin.

\section{Quality of samples}

Among the 500 patients included, 150 files were randomly selected for an evaluation of the quality of the samples taken. Two criteria were analyzed: the site of biopsies (antrum alone, corpus alone, corpus and antrum together) and the use of antisecretory agents and/or antibiotics for any reason by the patient within 4 weeks of the endoscopy.

\section{Statistical analysis}

First a descriptive analysis was performed in order to determine the prevalence of $H$. pylori in this study population. Second a univariate analysis was performed using a logistic regression and a multivariate analysis using a binomial logistic regression in order to identify variables associated with the presence of H. pylori infection. Variables included in this model were sex, age, tobacco consumption, alcohol consumption and race. A univariate analysis was performed for the quality of sample analysis. A P $<0.05$ was considered significant.

\section{Results}

Among the 1,351 eligible files, 538 files were analyzed, of which, 38 files were excluded because of incomplete or absent endoscopy reports. The remaining 500 files were retained for further study.

\section{Population characteristics}

The study population ( $\mathrm{n}=500$ patients) had an average age of $58 \pm 8$ years with a greater proportion of women $(57 \%$; $286 / 500)$ and Caucasians $(70 \%$; 350/500). The most often reported symptoms at the time of endoscopy were epigastric pain $(44 \% ; 218 / 500)$ and pyrosis $(24 \% ; 122 / 500)$. A total of $32 \%$ $(159 / 500)$ of the patients reported having more than one symptom at the time of the endoscopy. The detailed characteristics of the population are shown in Table 1. Smoking status and alcohol use were not reported in all files and were available for only 331 and 317 patients respectively.

\section{Prevalence of $\boldsymbol{H}$. pylori}

The prevalence of $H$. pylori in our population was $13.0 \%$ $(65 / 500)$. The prevalence was comparable among men and women, as well as in the age groups under and over 50 years old. We did not notice any difference between smokers and non-smokers or between people who drink more than 10 glasses of alcohol per week compared to those who consumed less than 10 (Table 2). The prevalence was, however, significantly different depending on the country of origin of the patients (Table 2). It was higher in African $(25.0 \% ; 8 / 32)$, Asian $(30.8 \% ; 4 / 13)$ and South American $(34.9 \% ; 15 / 43)$ groups compared to the Caucasian group $(8.0 \% ; 28 / 350)$. This difference was still significant when adjusted for smoking status, age, sex and alcohol consumption in the multivariate analysis (95\% confident interval odds ratio (OR) $3.9(1.1-14.0) \mathrm{P}<$ $0.05 ; 6.7(1.7-26.5) \mathrm{P}<0.05$ and $3.7(1.3-10.1) \mathrm{P}<0.05$ respectively).

\section{Location of the specimens}

The biopsies were performed in two distinct locations (the antrum and the gastric corpus) in $23 \%$ of the patients (34/150) and on one location (antrum or corpus) in 77\% (116/150) patients. When there was only one biopsy location, antral (72\%; $83 / 116$ ) biopsies were performed more often than fundic biopsies $(28 \%$; 33/116). The prevalence of $H$. pylori was not significantly higher when biopsies were performed at two different locations than compared to one ( $10 \%$ vs. $12 \%, \mathrm{P}=0.83)$ (Table 3). 
Table 1. Demographics and Chief Complaints of All Patients on the Day of Their EGD for $H$. pylori Infection Detection $(\mathrm{N}=$ 500)

\begin{tabular}{|c|c|c|}
\hline & $\mathbf{N}$ & $\%$ \\
\hline Male sex & 214 & $43 \%$ \\
\hline Age: years mean $\pm \mathrm{SD}$ & $58 \pm 8$ & \\
\hline$\leq 50$ years old & 174 & $35 \%$ \\
\hline Current smoker (tobacco) ${ }^{\mathrm{a}}$ & 89 & $27 \%$ \\
\hline Alcohol $^{\mathrm{b}}$ (> 10 consumptions per week) & 49 & $16 \%$ \\
\hline \multicolumn{3}{|l|}{ Race $(n=438)$} \\
\hline Caucasian & 350 & $70 \%$ \\
\hline South American & 43 & $9 \%$ \\
\hline African & 32 & $6 \%$ \\
\hline Asian & 13 & $3 \%$ \\
\hline Unknown & 62 & $12 \%$ \\
\hline \multicolumn{3}{|l|}{ Symptoms $(\mathrm{n}=500)$} \\
\hline Epigastric pain & 218 & $44 \%$ \\
\hline Pyrosis/GERD & 122 & $24 \%$ \\
\hline Dysphagia & 61 & $12 \%$ \\
\hline Anemia & 60 & $12 \%$ \\
\hline Nausea/vomiting & 56 & $11 \%$ \\
\hline Hematemesis & 43 & $9 \%$ \\
\hline Loss of appetite & 39 & $8 \%$ \\
\hline Diarrhea & 22 & $4 \%$ \\
\hline Other & 35 & $7 \%$ \\
\hline \multicolumn{3}{|l|}{ Number of symptoms $(n=500)$} \\
\hline 1 symptom & 341 & $68 \%$ \\
\hline 2 symptoms & 132 & $26 \%$ \\
\hline 3 symptoms & 23 & $5 \%$ \\
\hline 4 symptoms & 4 & $1 \%$ \\
\hline
\end{tabular}

aSmoking status information is available only for 331 patients; ${ }^{b}$ Alcohol consumption information is available only for 317 patients. EGD: esophagogastroduodenoscopy; SD: standard deviation; GERD: gastroesophageal reflux disease; $H$. pylori: Helicobacter pylori.

\section{Pharmacological factors}

A total of $39.3 \%(59 / 150)$ of the patients had taken antisecretory agents and/or antibiotics for any indication within 4 weeks of the EGD (Table 3). These patients did not have a significantly lower prevalence of $H$. pylori on their samples than untreated patients $(12 \%$ vs. $11 \%, \mathrm{P}=0.73)$ (Table 3$)$.

\section{Discussion}

In this cohort of symptomatic patients referred for EGD and $H$. pylori biopsies, we found an overall prevalence of $H$. pylori of only $13 \%$. This is the most recent Canadian study on the sub- ject and the only one in the province of Quebec to our knowledge. The prevalence found is lower than those of previous Canadian studies that showed a prevalence of between $20 \%$ and $30 \%[13,14]$. Several factors can explain this difference.

First, there were no Canadian First Nations members in this study. Canadian First Nations members are at a higher risk of carrying $H$. pylori with a prevalence of almost $40 \%$ in a recent study and up to $95 \%$ in a study conducted within a Cree population in northern Manitoba $[15,16,23]$. Knowing that the last Canadian census counted 1,400,685 First Nations people in Canada, or $4 \%$ of the population, it is likely that the lack of representation of this population in this study slightly underestimates the actual prevalence of $H$. pylori in the province Quebec.

Second, most of the prevalence studies found in the literature were done using serological tests, which are much less specific and can have up to $30 \%$ false positive results [10, 18]. In this study, we used histopathological assessment of $H$. pylori as the diagnostic criterion, which constitutes the Gold Standard according to the experts $[4,18,24]$. This important difference in methodology may explain the higher prevalence of $H$. pylori infection in other studies.

Third, $70 \%$ of patients in this study were of Caucasian race. Within the Caucasian patients, only $8 \%$ of symptomatic patients had $H$. pylori infection on their biopsies results, explaining our overall low prevalence. We believe that these results mark the downward trend in the prevalence of $H$. $p y$ lori infection in Western countries recently observed by other teams $[12,25]$. There have been major improvements in the management of $H$. pylori infection in recent years, particularly regarding the efficacy of antibiotic treatment, which now allows an eradication rate of more than $85 \%[11,26,27]$. Improvement in the lifestyle quality and in the public health services in Western countries has also helped reducing the incidence of $H$. pylori infection $[5,11,15,26]$. Improvement in household hygienic practices has decreased the transmission of $H$. pylori during childhood, which is the most common period to catch this infection $[1,13]$. This study confirms that among the Canadian population, non-Caucasian immigrants are at an increased risk of carrying $H$. pylori (OR, $3.7-6.7$ ) when compared to the Caucasian population. Despite the small sample size that limits our statistical power and increases our confidence intervals, our results remain very significant $(\mathrm{P}<0.05)$ even after adjustment for other classic risk factors (age, sex, smoking status, alcohol consumption) and we believe that these numbers adequately represent the population of Canada. These results are consistent with earlier studies on this subject $[1,13]$ and show that non-Caucasian immigrants should be considered at a higher risk of carrying $H$. pylori infection.

Finally, we observed that only $23 \%$ of the sampled biopsies had been done both in the antrum and in the gastric corpus. It is well established that biopsies at several sites reduce the number of false negatives and are part of the $\mathrm{Ca}$ nadian guidelines, as well as of the recommendations of the majority of the medical societies [6, 20, 28-31]. In a Canadian study, El-Zimaity et al (2013) obtained similar results showing that among a sample of 150 patients, only $40 \%$ of the biopsies were taken from both the corpus and the antrum 
Table 2. Comparison of Patients' H. pylori Status in Function of Their Demographic Characteristics

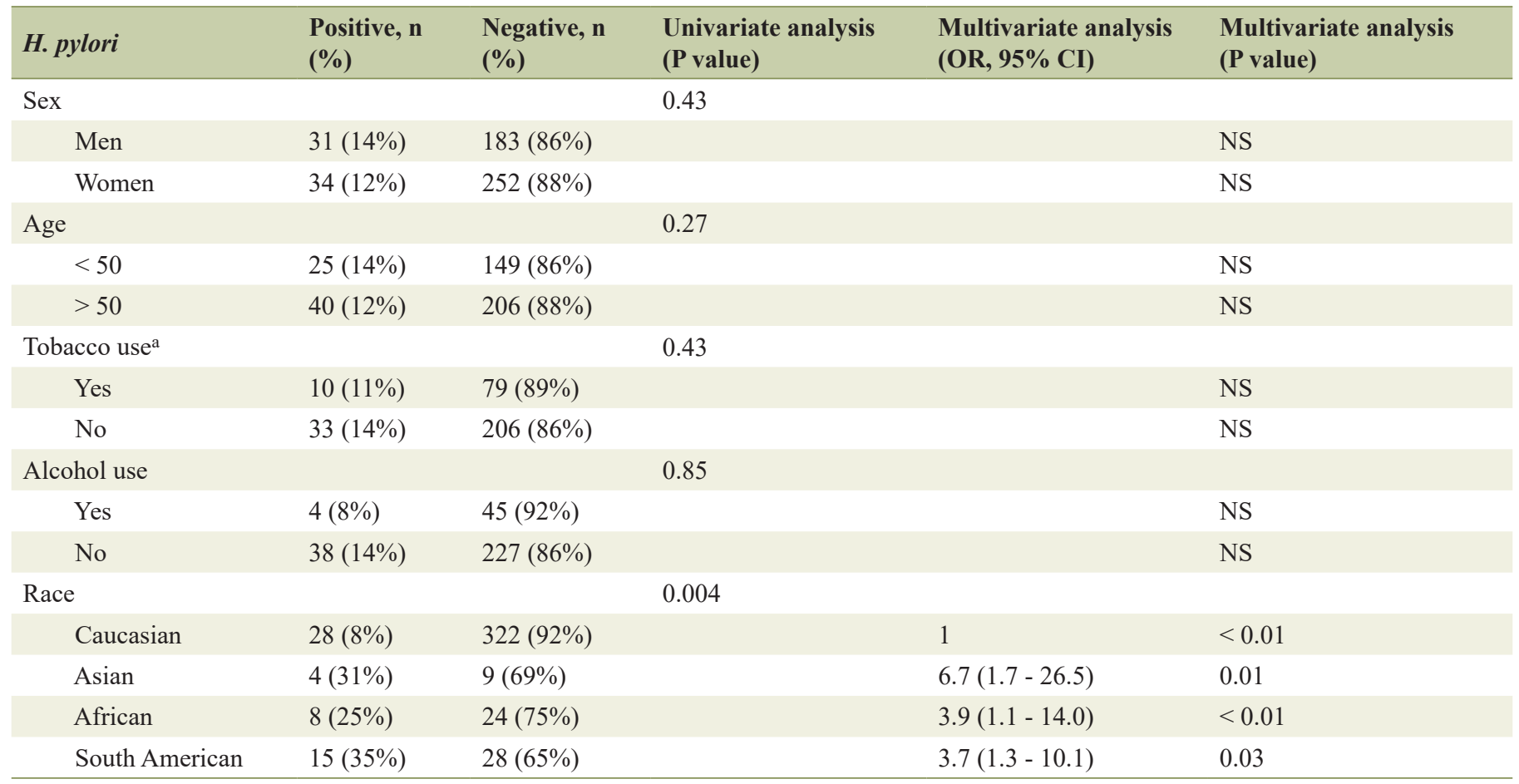

aAlcohol use is defined as more than 10 drinks per week. OR: odds ratio; Cl: confidence interval; H. pylori: Helicobacter pylori; NS: non-significant.

[22]. They then concluded that this error led to at least $15 \%$ false negatives. We could not show a significant difference in the prevalence of $H$. pylori infection when the biopsies were done at both sites. However, this is a secondary outcome of this study and we do not have the statistical power to make any conclusions. It is possible that the prevalence of $H$. $p y$ lori in our population was underestimated by this sampling error. We also know that taking antisecretory agents and/ or antibiotics may alter the results of the biopsies. It is recommended that PPIs be stopped 2 weeks before testing and antibiotics 1 month earlier $[16,18,26]$. However, clinicians and patients are reluctant to stop PPIs for 2 weeks before EGD, especially symptomatic cases. We observed that $39 \%$ of our patients were taking either an antisecretory agent or an antibiotic within 4 weeks of the EGD. A similar percentage $(47 \%)$ of patients on PPI at the time of EGD was observed in the El-Zimaity study [22].
This study has several limitations, with the most notable being that $H$. pylori prevalence was evaluated from a population of symptomatic patients referred in a quaternary hospital for EGD during which biopsies for $H$. pylori detection were taken. This led to a potential selection bias because patients undergoing endoscopy for upper gastrointestinal symptoms in our institution most likely do not represent the general Canadian population. H. pylori can present in both symptomatic and asymptomatic patients. We would expect symptomatic patients to have a higher prevalence of $H$. pylori than the general population, leading to an overestimation of the overall prevalence of $H$. pylori infection. Even in this selected population, there was an overall very low prevalence $(13 \%)$ of $H$. pylori infection. In comparison, the Canadian Adult Dyspepsia Empiric Treatment-Prompt Endoscopy (CADET-PE) study, a prospective cohort study published in 2003, which also looked at a population of symptomatic patients referred for endoscopy,

Table 3. Comparison of $H$. pylori Status in Function of Biopsies Location and PPI or Antibiotics Use at the Time of EGD

\begin{tabular}{llll}
$\boldsymbol{H}$. pylori & Positive, $\mathbf{n}(\%)$ & Negative, $\mathbf{n}(\mathbf{\%})$ & Univariate analysis (P value) \\
\hline $\begin{array}{l}\text { Biopsies location } \\
\quad \text { Corpus or antrum }\end{array}$ & $12(10 \%)$ & $104(90 \%)$ & 0.83 \\
$\quad$ Corpus and antrum & $4(12 \%)$ & $30(88 \%)$ & 0.73 \\
PPI or antibiotics at the time of EGD & & \\
Yes & $7(12 \%)$ & $51(88 \%)$ & \\
No & $9(11 \%)$ & $76(89 \%)$ & \\
\hline
\end{tabular}

aOnly done for the first 150 patients. EGD: esophagogastroduodenoscopy; PPIs: proton pump inhibitors; H. pylori: Helicobacter pylori. 
showed a prevalence of biopsy-proven $H$. pylori infection of $30 \%$ in their cohort of 1,040 patients [14]. This lends validity to the hypothesis that the diminution in the prevalence of $H$. pylori infection observed in this study is a result of the improvement in the treatment and prevention of this infection and not only the result of a selection bias. Another limitation of this study is that we did not exclude patients who had already been treated in the past for $H$. pylori infection. This information bias could lead to an underestimation of the true prevalence of $H$. pylori. However, C13 urea breath tests are used for the confirmation of $H$. pylori eradication in our institution and EGD is not performed routinely. We believe that this could only represent a minority of patients and does not have a major impact on our results.

\section{Conclusions}

In this population of symptomatic patients from Quebec referred for EGD and H. pylori biopsies, we observed a prevalence of $13 \%$ of $H$. pylori infection, which is lower than the numbers observed so far in Canada. Among this population, non-Caucasian immigrants were by far the most at risk of carrying $H$. pylori. The Caucasian population had a prevalence of only $8 \%$ of $H$. pylori. We believe that these results mark a downward trend in the prevalence of $H$. pylori infection in Western countries. Finally, we observed that a majority of the biopsies sampled were not made as per guidelines, probably leading to under-diagnosis of this pathology. We recommend that clinicians be vigilant and always biopsy both the gastric antrum and corpus for any patient who has suspected symptoms of $H$. pylori infection.

\section{Acknowledgments}

The authors would like to acknowledge the participation of the CHUM Gastroenterology and Pathology Divisions in this study.

\section{Financial Disclosure}

This research and publication were founded by the authors' personal research funds and received no particular funding.

\section{Conflict of Interest}

None to declare.

\section{Informed Consent}

Specific informed consent was not necessary for this study because of its retrospective nature. All patients at our institution are aware that their chart information might be used retrospectively for research purpose.

\section{Author Contributions}

PW contributed to analysis and interpretation of data; drafting of the manuscript; and critical revision of the manuscript for important intellectual content. JR and GMH contributed to acquisition of data; analysis and interpretation of data; critical revision of the manuscript for important intellectual content. SS was involved in critical revision of the manuscript for important intellectual content. GS contributed to study concept and critical revision of the manuscript for important intellectual content. MB contributed to study concept and design, analysis and interpretation of data; drafting of the manuscript; and critical revision of the manuscript for important intellectual content.

\section{Data Availability}

The authors declare that data supporting the findings of this study are available within the article.

\section{References}

1. Eusebi LH, Zagari RM, Bazzoli F. Epidemiology of Helicobacter pylori infection. Helicobacter. 2014;19(Suppl 1): $1-5$.

2. Wang AY, Peura DA. The prevalence and incidence of Helicobacter pylori-associated peptic ulcer disease and upper gastrointestinal bleeding throughout the world. Gastrointest Endosc Clin N Am. 2011;21(4):613-635.

3. Cid TP, Fernandez MC, Benito Martinez S, Jones NL. Pathogenesis of Helicobacter pylori infection. Helicobacter. 2013;18(Suppl 1):12-17.

4. Sugano K, Tack J, Kuipers EJ, Graham DY, El-Omar EM, Miura S, Haruma K, et al. Kyoto global consensus report on Helicobacter pylori gastritis. Gut. 2015;64(9):13531367.

5. Chey WD, Wong BC, Practice Parameters Committee of the American College of G. American College of Gastroenterology guideline on the management of Helicobacter pylori infection. Am J Gastroenterol. 2007;102(8):18081825.

6. Fallone CA, Chiba N, van Zanten SV, Fischbach L, Gisbert JP, Hunt RH, Jones NL, et al. The Toronto consensus for the treatment of helicobacter pylori infection in adults. Gastroenterology. 2016;151(1):51-69 e14.

7. Zamani M, Ebrahimtabar F, Zamani V, Miller WH, Alizadeh-Navaei R, Shokri-Shirvani J, Derakhshan MH. Systematic review with meta-analysis: the worldwide prevalence of Helicobacter pylori infection. Aliment Pharmacol Ther. 2018;47(7):868-876.

8. Everhart JE, Kruszon-Moran D, Perez-Perez GI, Tralka TS, McQuillan G. Seroprevalence and ethnic differences in Helicobacter pylori infection among adults in the United States. J Infect Dis. 2000;181(4):1359-1363.

9. Robertson MS, Cade JF, Savoia HF, Clancy RL. Helicobacter pylori infection in the Australian community: cur- 
rent prevalence and lack of association with $\mathrm{ABO}$ blood groups. Intern Med J. 2003;33(4):163-167.

10. Chiba N, Veldhuyzen Van Zanten SJ. 13C-Urea breath tests are the noninvasive method of choice for Helicobacter pylori detection. Can J Gastroenterol. 1999;13(8):681683.

11. Fallone CA, Barkun AN, Szilagyi A, Herba KM, Sewitch M, Martel M, Fallone SS. Prolonged treatment duration is required for successful Helicobacter pylori eradication with proton pump inhibitor triple therapy in Canada. Can J Gastroenterol. 2013;27(7):397-402.

12. Bures J, Kopacova M, Koupil I, Seifert B, Skodova Fendrichova M, Spirkova J, Vorisek V, et al. Significant decrease in prevalence of Helicobacter pylori in the Czech Republic. World J Gastroenterol. 2012;18(32):4412-4418.

13. Naja F, Kreiger N, Sullivan T. Helicobacter pylori infection in Ontario: prevalence and risk factors. Can J Gastroenterol. 2007;21(8):501-506.

14. Thomson AB, Barkun AN, Armstrong D, Chiba N, White RJ, Daniels S, Escobedo S, et al. The prevalence of clinically significant endoscopic findings in primary care patients with uninvestigated dyspepsia: the Canadian Adult Dyspepsia Empiric Treatment - Prompt Endoscopy (CADET-PE) study. Aliment Pharmacol Ther. 2003;17(12):1481-1491.

15. Jones N, Chiba N, Fallone C, Thompson A, Hunt R, Jacobson K, Goodman K, et al. Helicobacter pylori in First Nations and recent immigrant populations in Canada. Can J Gastroenterol. 2012;26(2):97-103.

16. Goodman KJ, Jacobson K, Veldhuyzen van Zanten S. Helicobacter pylori infection in Canadian and related Arctic Aboriginal populations. Can J Gastroenterol. 2008;22(3):289-295.

17. Malfertheiner P, Megraud F, O'Morain CA, Gisbert JP, Kuipers EJ, Axon AT, Bazzoli F, et al. Management of Helicobacter pylori infection-the Maastricht V/Florence Consensus Report. Gut. 2017;66(1):6-30.

18. Ling D. Carbon-13 urea breath test for Helicobacter pylori infection in patients with uninvestigated ulcer-like dyspepsia: an evidence-based analysis. Ont Health Technol Assess Ser. 2013;13(19):1-30.

19. Gatta L, Vakil N, Ricci C, Osborn JF, Tampieri A, Perna F, Miglioli M, et al. Effect of proton pump inhibitors and antacid therapy on $13 \mathrm{C}$ urea breath tests and stool test for Helicobacter pylori infection. Am J Gastroenterol. 2004;99(5):823-829.

20. Satoh K, Kimura K, Taniguchi Y, Kihira K, Takimoto T, Saifuku K, Kawata H, et al. Biopsy sites suitable for the diagnosis of Helicobacter pylori infection and the assess- ment of the extent of atrophic gastritis. Am J Gastroenterol. 1998;93(4):569-573.

21. Wang YK, Kuo FC, Liu CJ, Wu MC, Shih HY, Wang SS, Wu JY, et al. Diagnosis of Helicobacter pylori infection: Current options and developments. World J Gastroenterol. 2015;21(40):11221-11235.

22. El-Zimaity H, Serra S, Szentgyorgyi E, Vajpeyi R, Samani A. Gastric biopsies: the gap between evidence-based medicine and daily practice in the management of gastric Helicobacter pylori infection. Can J Gastroenterol. 2013;27(10):e25-30.

23. Bernstein CN, McKeown I, Embil JM, Blanchard JF, Dawood M, Kabani A, Kliewer E, et al. Seroprevalence of Helicobacter pylori, incidence of gastric cancer, and peptic ulcer-associated hospitalizations in a Canadian Indian population. Dig Dis Sci. 1999;44(4):668-674.

24. Malfertheiner P. Diagnostic methods for H. pylori infection: Choices, opportunities and pitfalls. United European Gastroenterol J. 2015;3(5):429-431.

25. Hooi JKY, Lai WY, Ng WK, Suen MMY, Underwood FE, Tanyingoh D, Malfertheiner P, et al. Global prevalence of helicobacter pylori infection: systematic review and meta-analysis. Gastroenterology. 2017;153(2):420-429.

26. Cheung J, Goodman KJ, Girgis S, Bailey R, Morse J, Fedorak RN, Geary J, et al. Disease manifestations of Helicobacter pylori infection in Arctic Canada: using epidemiology to address community concerns. BMJ Open. 2014;4(1):e003689.

27. Ford AC, Marwaha A, Sood R, Moayyedi P. Global prevalence of, and risk factors for, uninvestigated dyspepsia: a meta-analysis. Gut. 2015;64(7):1049-1057.

28. Hazell SL, Borody TJ, Gal A, Lee A. Campylobacter pyloridis gastritis I: Detection of urease as a marker of bacterial colonization and gastritis. Am J Gastroenterol. 1987;82(4):292-296.

29. Dixon MF, Genta RM, Yardley JH, Correa P. Classification and grading of gastritis. The updated Sydney System. International Workshop on the Histopathology of Gastritis, Houston 1994. Am J Surg Pathol. 1996;20(10):11611181.

30. Graham DY, Opekun AR, Hammoud F, Yamaoka Y, Reddy R, Osato MS, El-Zimaity HM. Studies regarding the mechanism of false negative urea breath tests with proton pump inhibitors. Am J Gastroenterol. 2003;98(5):10051009.

31. Weston AP, Campbell DR, Hassanein RS, Cherian R, Dixon A, McGregor DH. Prospective, multivariate evaluation of CLOtest performance. Am J Gastroenterol. 1997;92(8):1310-1315. 